\title{
Fertilization in vitro of hamster and mouse eggs in a chemically defined medium
}

\author{
K. Niwa, H. Imai, C. I. Kim and A. Iritani \\ Department of Animal Science, College of Agriculture, \\ Kyoto University, Kyoto 606, Japan
}

\begin{abstract}
Summary. Hamster and mouse eggs with follicular cells were penetrated by epididymal spermatozoa in a modified Krebs-Ringer-bicarbonate solution known to be suitable for fertilization of rat eggs in vitro. The highest proportion (84-88\%) of hamster eggs penetrated was observed when 6-30 eggs with follicular cells were introduced into $10 \mu \mathrm{l}$ sperm suspension. Greater volumes of sperm suspension reduced the proportions of eggs fertilized, while increased numbers of eggs in the same volume gave greater penetration rates. No fertilization was observed when 2130 denuded hamster eggs were introduced into $10-100 \mu \mathrm{l}$ sperm suspension, indicating that capacitation and/or acrosome reaction of hamster epididymal spermatozoa was induced only by the post-ovulatory oviduct contents in this medium. However, when small numbers (10-20) of mouse eggs with or without follicular cells were incubated in a large volume ( $400 \mu \mathrm{l})$ of sperm suspension, $84-96 \%$ and $91 \%$ were penetrated, respectively, suggesting a lack of importance of the products of ovulation on mouse sperm capacitation. The incidence of polyspermy was very low for the hamster $(0-13 \%)$ and mouse eggs $(0-10 \%)$.
\end{abstract}

\section{Introduction}

Since the first achievement of in-vitro fertilization of hamster (Yanagimachi \& Chang, 1963, 1964) and mouse eggs (Iwamatsu \& Chang, 1969) by epididymal spermatozoa, various kinds of media with different chemical compositions have been used for fertilizations in vitro. Although it was reported by Hanada \& Chang (1976) that very low proportions of hamster eggs with follicular cells are fertilized by epididymal spermatozoa in a modified Krebs-Ringer-bicarbonate (m-KRB) solution suitable for rabbit (Brackett, 1970) or rat eggs (Toyoda \& Chang, 1974), much higher penetration rates occur in Tyrode's solution and modified Medium 199 containing follicular fluids (Barros \& Austin, 1967; Yanagimachi, 1969a, b; Gwatkin \& Andersen, 1969) or blood serum (Yanagimachi, 1970; Miyamoto \& Chang, 1972b). Gwatkin, Andersen \& Hutchinson (1972) reported that the cumulus components play an important role in the capacitation of spermatozoa and fertilization of hamster eggs in vitro. This cumulus-induced capacitation, however, occurs in a modified Medium 199, but not in Tyrode's solution (Yanagimachi, 1969a; Gwatkin, 1977). Although mouse eggs can be fertilized in a m-KRB solution (Toyoda, Yokoyama \& Hoshi, 1971; Miyamoto \& Chang, 1972a; Pavlok \& McLaren, 1972; Hoppe \& Pitts, 1973), its chemical composition is varied slightly by different workers. The present study was to investigate the in-vitro fertilizability of hamster and mouse eggs in a mKRB solution suitable for rat eggs (Toyoda \& Chang, 1974). 


\section{Materials and Methods}

The medium used was the m-KRB solution $\left(94.6 \mathrm{~mm}-\mathrm{NaCl}, 4.78 \mathrm{mM}-\mathrm{KCl}, 1.71 \mathrm{mM}-\mathrm{CaCl}_{2}\right.$, $1.19 \mathrm{~mm}-\mathrm{KH}_{2} \mathrm{PO}_{4}, 1.19 \mathrm{~mm}-\mathrm{MgSO}_{4}, 25.07 \mathrm{~mm}-\mathrm{NaHCO}_{3}, 21.58 \mathrm{~mm}$-sodium lactate, $0.5 \mathrm{~mm}$ sodium pyruvate, $5.56 \mathrm{~mm}$-glucose, $4 \mathrm{mg} \mathrm{BSA} / \mathrm{ml}, 50 \mu \mathrm{g}$ streptomycin sulphate $/ \mathrm{ml}$ and $75 \mu \mathrm{g}$ potassium penicillin $\mathrm{G} / \mathrm{ml}$ ) described by Toyoda \& Chang (1974).

Hamsters. A tubule of an excised cauda epididymidis from mature male hamsters weighing 95-150 $\mathrm{g}$ was cut with sharp scissors and a small drop of the emerging sperm mass was taken with a sterile glass needle and placed into $500 \mu \mathrm{l}$ medium covered with sterilized warm paraffin oil (Nakarai Chemical Co.) previously equilibrated with $5 \% \mathrm{CO}_{2}$ in air in the presence of a small volume of saline, in a plastic culture dish $(35 \times 11 \mathrm{~mm}$ : Toyoshima Seisaku-sho). About $5 \mathrm{~min}$ after preparation of this sperm suspension, $40 \mu \mathrm{l}$ were placed with a micropipette (Ependorf) in $400 \mu \mathrm{l}$ medium prepared in another dish. From the diluted sperm suspension, a $10 \mu \mathrm{l}$ volume containing 3-20 × $10^{4}$ spermatozoa was again introduced into $0,10,40$ and $90 \mu \mathrm{l}$ of the medium, which was covered with paraffin oil, in a large plastic dish $(60 \times 15 \mathrm{~mm})$ so that the final volumes of the sperm suspension and the sperm concentrations at insemination were 10, 20, 50 and $100 \mu \mathrm{l}$ and $3-20 \times 10^{6}, 1.5-10 \times 10^{6}, 0.6-4 \times 10^{6}$ and $0.3-2 \times 10^{6}$ spermatozoa $/ \mathrm{ml}$, respectively. Mature female hamsters weighing $104-211 \mathrm{~g}$ were induced to superovulate by i.p. injection of 25 i.u. PMSG (Serotropin: Teikoku-Zoki Co.) on the evening of the post-oestrous vaginal discharge, followed by i.p. injection of 25 i.u. hCG (Puberogen: Sankyo Co.) 48 h later. The eggs in cumulus clots were dissected out from the oviducts under oil in a dish 14-15 h after the hCG injection and 1-5, 6-10,11-20 or 21-30 eggs were introduced into each sperm suspension.

Mice. A mouse sperm suspension was prepared by mincing the cauda epididymidis of a mature male ICR mouse, weighing 31-38 g, in 500 $\mu$ l medium covered with paraffin oil in a plastic culture dish $(35 \times 11 \mathrm{~mm})$. About $5 \mathrm{~min}$ later, $20 \mu \mathrm{l}$ of this sperm suspension were added with a micropipette to $400 \mu \mathrm{l}$ medium in another dish. Mature female ICR mice weighing 20-30 $\mathrm{g}$ were induced to superovulate by i.p. injection of 5 i.u. PMSG and hCG $48-50 \mathrm{~h}$ apart. The eggs in cumulus clots were recovered from oviducts isolated $14 \mathrm{~h}$ after injection of hCG and then 10-20 eggs were introduced into each sperm suspension. Sperm concentration at the insemination was $0.22-0.45 \times 10^{6}$ spermatozoa $/ \mathrm{ml}$.

Denudation and insemination. For the removal of follicular cells and other products of ovulation surrounding the eggs, hamster and mouse eggs in cumulus clots were treated for 5-10 min with $0.1 \%$ hyaluronidase (Type I: Sigma Chemical Co.) in the medium without BSA. The denuded eggs were washed twice in the medium before introducing into sperm suspensions.

After insemination all preparations were incubated in a $\mathrm{CO}_{2}$ incubator saturated with $5 \%$ $\mathrm{CO}_{2}$ in air at $37^{\circ} \mathrm{C}$. After incubation for 8-8.5 h for hamster eggs and 5-5.5 h for mouse eggs, the eggs were picked up and mounted in toto on a slide (Chang, 1952). After fixation with $2 \cdot 5 \%$ glutaraldehyde and $10 \%$ neutral formalin (Toyoda \& Chang, 1974), the eggs were stained with $0.25 \%$ lacmoid and examined for the evidence of sperm penetration and fertilization. Penetrated eggs were those which had been penetrated by spermatozoa, including those with spermatozoa in the perivitelline space. Eggs with an enlarged sperm head(s) or male pronucleus(ei) in the vitellus were considered to be undergoing fertilization.

\section{Results}

\section{The motility of hamster and mouse epididymal spermatozoa}

The motility of hamster spermatozoa was greatly decreased after $2-3 \mathrm{~h}$ in the absence of eggs with follicular cells or in the presence of denuded eggs. When eggs with follicular cells were introduced, the spermatozoa exhibited whiplash or activated motility which was maintained for 
about $8 \mathrm{~h}$. This became more conspicuous as the number of eggs introduced was increased or as the volume of the sperm suspension was decreased. On the other hand, no differences in the motility of mouse spermatozoa 5-5.5 h after insemination of eggs with or without follicular cells were observed.

\section{Fertilization of hamster eggs with or without follicular cells}

Various numbers of hamster eggs with or without follicular cells were exposed to different volumes of the sperm suspensions. From the results in Table 1, it can be seen that when 6-30 eggs with follicular cells were exposed to $10 \mu \mathrm{l}$ sperm suspension very high proportions (84$88 \%$ ) of eggs were undergoing fertilization 8-8.5 h after insemination. In contrast, when $1-5$ eggs were introduced into $10 \mu \mathrm{l}$ sperm suspension, the proportion of eggs undergoing fertilization was only $42 \%$. Increased numbers of eggs in the same sperm suspension volume led to greater fertilization rates, while increasing sperm suspension volume for the same number of eggs reduced the proportions of eggs fertilized. No fertilization was observed when 21-30 eggs without follicular cells were introduced into $10-100 \mu \mathrm{l}$ sperm suspension.

Table 1. Fertilization of hamster eggs with or without follicular cells in a modified Krebs-Ringerbicarbonate medium

\begin{tabular}{ccccccc}
\hline No. of eggs & $\begin{array}{c}\text { Vol. of medium } \\
\text { during } \\
\text { incubation } \\
\text { introduced }\end{array}$ & $\begin{array}{c}\text { No. of } \\
\text { tests }\end{array}$ & $\begin{array}{c}\text { No. of eggs } \\
\text { examined }\end{array}$ & $\begin{array}{c}\text { No. of eggs } \\
\text { penetrated } \\
(\%)\end{array}$ & $\begin{array}{c}\text { No. of eggs } \\
\text { undergoing } \\
\text { fertilization } \\
(\%)\end{array}$ & $\begin{array}{c}\text { No. of } \\
\text { polyspermic } \\
\text { eggs } \\
(\%)\end{array}$ \\
\hline $1-5$ & 10 & 6 & 24 & $10(42)$ & $10(42)$ & $1(10)$ \\
& 20 & 6 & 23 & $8(35)$ & $8(35)$ & $1(13)$ \\
& 50 & 9 & 33 & $6(18)$ & $6(18)$ & $0(0)$ \\
$6-10$ & 100 & 7 & 30 & $0(0)$ & $0(0)$ & - \\
& 10 & 4 & 25 & $22(88)$ & $22(88)$ & $0(0)$ \\
& 20 & 4 & 29 & $22(76)$ & $22(76)$ & $1(6)$ \\
$11-20$ & 50 & 5 & 38 & $13(34)$ & $13(34)$ & $1(8)$ \\
& 100 & 5 & 36 & $4(11)$ & $4(11)$ & $0(0)$ \\
& 10 & 3 & 40 & $34(85)$ & $34(85)$ & $1(3)$ \\
$21-30$ & 20 & 5 & 73 & $57(78)$ & $57(78)$ & $5(9)$ \\
& 50 & 5 & 79 & $57(72)$ & $57(72)$ & $4(7)$ \\
& 100 & 3 & 50 & $28(56)$ & $28(56)$ & $1(4)$ \\
& 10 & 2 & 51 & $43(84)$ & $43(84)$ & $2(5)$ \\
$21-30^{*}$ & 20 & 2 & 49 & $41(84)$ & $41(84)$ & $2(5)$ \\
& 50 & 2 & 45 & $35(77)$ & $35(77)$ & $2(6)$ \\
& 100 & 3 & 77 & $59(77)$ & $59(77)$ & $5(8)$ \\
& 10 & 3 & 68 & $0(0)$ & - & - \\
& 20 & 3 & 67 & $0(0)$ & - & - \\
& 50 & 3 & 67 & $0(0)$ & - & - \\
\hline
\end{tabular}

Eggs were examined $8-8.5 \mathrm{~h}$ after insemination.

* Denuded eggs.

The incidence of polyspermy was very low (0-13\%) and was not correlated with the number of eggs introduced or with the volume of the sperm suspension at the insemination.

\section{Fertilization of mouse eggs with or without follicular cells}

As shown in Table 2, of 221 mouse eggs with follicular cells from 4 experiments, 202 (91\%) were penetrated and 198 (90\%) were undergoing fertilization in the rat medium. A very high pro- 
Table 2. Fertilization of mouse eggs with or without follicular cells in a modified Krebs-Ringer-bicarbonate medium

\begin{tabular}{ccccc}
\hline Exp. no. & $\begin{array}{c}\text { No. of eggs } \\
\text { examined }\end{array}$ & $\begin{array}{c}\text { No. of eggs } \\
\text { penetrated } \\
(\%)\end{array}$ & $\begin{array}{c}\text { No. of eggs } \\
\text { undergoing } \\
\text { fertilization } \\
(\%)\end{array}$ & $\begin{array}{c}\text { No. of } \\
\text { polyspermic } \\
\text { eggs } \\
(\%)\end{array}$ \\
\hline 1 & 58 & $49(84)$ & $49(84)$ & $1(2)$ \\
2 & 89 & $85(96)$ & $81(91)$ & $5(6)$ \\
3 & 30 & $26(87)$ & $26(87)$ & $0(0)$ \\
4 & 44 & $42(95)$ & $42(95)$ & $4(10)$ \\
$5^{*}$ & 78 & $71(91)$ & $69 \dagger(88)$ & $4(6)$ \\
\hline
\end{tabular}

Eggs were examined 5-5.5 h after insemination.

* Denuded eggs.

$\dagger$ Of 60 eggs with pronuclei 21 (35\%) were digynic triploids.

portion (91\%) of denuded eggs was also penetrated. The overall incidences of polyspermy were only $5 \%$ in the eggs with follicular cells and $6 \%$ in the denuded eggs. However, $35 \%$ of the denuded eggs penetrated and with pronuclei were digynic triploids.

\section{Discussion}

A special medium for each species has been used by different workers for in-vitro fertilization of mammalian eggs. It is, however, questionable as to why each species requires a different medium. If one medium with the same chemical composition could be used for fertilization in vitro of the gametes of different species, it would be easier to compare experiments and to assess the precise requirements for fertilization of different species. In the present study, it has been clearly shown that hamster and mouse eggs with follicular cells can be fertilized in a modified Krebs-Ringer-bicarbonate solution known to be suitable for the rat (Toyoda \& Chang, 1974; Niwa \& Chang, 1974a, b). Although Hanada \& Chang (1976) obtained only a low fertilization rate $(5 \cdot 1 \%)$ for hamster eggs with follicular cells in this rat medium, this was probably due to the large volume $(400 \mu \mathrm{l})$ of the sperm suspension used and the comparatively low number of eggs introduced (average 23), because the present results show that there is an intimate interaction between the volume of the fertilization medium and the numbers of eggs introduced for in-vitro fertilization of hamster eggs in the rat medium, indicating the importance of the cumulus cells and/or follicular fluid round the eggs for fertilization. This is also shown by the failure of fertilization of denuded hamster eggs, although this could have been due to damage to the eggs during removal of the cumulus cells. This is in striking contrast to results with rat epididymal spermatozoa which can be capacitated during culture in medium without post-ovulatory oviduct contents (Niwa \& Chang, 1974a, b). In the absence of epididymal secretions in a modified Medium 199, the involvement of cumulus cells for capacitation of mouse spermatozoa in vitro has been reported (Gwatkin, Andersen \& Williams, 1974). However, the present results show that mouse epididymal spermatozoa could also be capacitated by preincubation in the rat medium without the products of ovulation because very high proportions $(84-96 \%$ and $91 \%)$ of eggs with or without follicular cells were penetrated even when there was a large volume ( $400 \mu \mathrm{l})$ of the sperm suspension and a comparatively small number (10-20) of eggs (Table 2).

Capacitation of hamster epididymal spermatozoa can be achieved during preincubation in modified Tyrode's solution (Bavister, 1969), but the acrosome reaction was only induced following the addition of the products of ovulation (Bavister, 1973). Of the post-ovulatory oviduct contents, the active component to induce sperm capacitation and/or the acrosome reaction may be different according to the medium used, because follicular fluid is effective in Tyrode's solution 
(Yanagimachi, 1969a) but the cumulus oophorus cells are the active component in Medium 199 (Gwatkin et al., 1972). In the present study, however, it was not examined which components of the products were effective. Since there is no difference in the penetration rates of hamster eggs with or without follicular cells when incubated with epididymal spermatozoa in Tyrode's solution containing heated hamster (Miyamoto \& Chang, 1972b) or rabbit serum (Tsunoda \& Chang, 1977), post-ovulatory oviduct contents may not have any advantageous effect on sperm capacitation when they exist with other biological fluids in the medium. On the other hand, such biological fluids may actually be disadvantageous for normal sperm capacitation because a high incidence, often as high as $100 \%$, of polyspermy is a common feature during in-vitro fertilization of hamster eggs in media with biological fluids (Yanagimachi, 1969a, b, 1970; Miyamoto \& Chang, 1972b; Tsunoda \& Chang, 1977), while the induction of capacitation of hamster epididymal spermatozoa by cumulus cells in vitro provides $100 \%$ penetration and complete monospermy (Gwatkin, 1977). A low incidence $(0-13 \%)$ of polyspermy was also observed in the present study in which hamster eggs with follicular cells were inseminated in a chemically defined medium without any other biological fluids.

In the present study, the sperm concentrations differed in the different volumes of medium but the numbers of spermatozoa were the same so that the eggs were exposed to similar numbers of spermatozoa. No penetration was observed when 1-5 eggs were inseminated in $100 \mu \mathrm{l}$ medium compared with $77 \%$ penetrated when $21-30$ eggs were inseminated in the same volume and with the same sperm concentration, indicating that the density of the post-ovulatory oviduct contents is the crucial factor affecting sperm penetration.

This work was supported by grants from the Ministry of Education of Japan (No. 456199) and the Ford Foundation (No. 740-0404).

\section{References}

Barros, C. \& Austin, C. R. (1967) In vitro fertilization and the sperm acrosome reaction in the hamster. $J$. exp. Zool. 166, 317-324.

Bavister, B.D. (1969) Environmental factors important for in vitro fertilization in the hamster. $J$. Reprod. Fert. 18, 544, Abstr.

Bavister, B.D. (1973) Capacitation of golden hamster spermatozoa during incubation in culture medium. $J$. Reprod. Fert. 35, 161-163.

Brackett, B.G. (1970) In vitro fertilization of mammalian ova. Adv. Biosci. 4, 73-94.

Chang, M.C. (1952) Fertilizability of rabbit ova and the effects of temperature in vitro on their subsequent fertilization and activation in vivo. J. exp. Zool. 121, 351-381.

Gwatkin, R.B.L. (1977) Fertilization Mechanisms in Man and Mammals. Plenum Press, New York.

Gwatkin, R.B.L. \& Andersen, O.F. (1969) Capacitation of hamster spermatozoa by bovine follicular fluid. Nature, Lond. 224, 1111-1112.

Gwatkin, R.B.L., Andersen, O.F. \& Hutchinson, C.F. (1972) Capacitation of hamster spermatozoa in vitro: the role of cumulus components. J. Reprod. Fert. 30, 389-394.

Gwatkin, R.B.L., Andersen, O.F. \& Williams, D.T. (1974) Capacitation of mouse spermatozoa in vitro: involvement of epididymal secretions and cumulus oophorus. J. Reprod. Fert. 41, 253-256.
Hanada, A. \& Chang, M.C. (1976) In-vitro fertilization of hamster eggs in different media and the stimulating effect of heterologous and homologous spermatozoa. J. Reprod. Fert. 46, 105-114.

Hoppe, P.C. \& Pitts, S. (1973) Fertilization in vitro and development of mouse ova. Biol. Reprod. 8, 420426.

Iwamatsu, T. \& Chang, M.C. (1969) In vitro fertilization of mouse eggs in the presence of bovine follicular fluid. Nature, Lond. 224, 919-920.

Miyamoto, H. \& Chang, M.C. (1972a) Development of mouse eggs fertilized in vitro by epididymal spermatozoa. J. Reprod. Fert. 30, 135-137.

Miyamoto, H. \& Chang, M.C. (1972b) Fertilization in vitro of mouse and hamster eggs after the removal of follicular cells. J. Reprod. Fert. 30, 309-312.

Niwa, K. \& Chang, M.C. (1974a) Effects of sperm concentration on the capacitation of rat spermatozoa. J. exp. Zool. 189, 353-356.

Niwa, K. \& Chang, M.C. (1974b) Various conditions for the fertilization of rat eggs in vitro. Biol. Reprod. 11, $463-469$.

Pavlok, A. \& McLaren, A. (1972) The role of cumulus cells and the zona pellucida in fertilization of mouse eggs in vitro. J. Reprod. Fert. 29, 91-97.

Toyoda, Y. \& Chang, M.C. (1974) Fertilization of rat eggs in vitro by epididymal spermatozoa and the development of eggs following transfer. J. Reprod. Fert. 36, 9-22. 
Toyoda, Y., Yokoyama, M. \& Hoshi, T. (1971) Studies on the fertilization of mouse eggs in vitro. I. In vitro fertilization of eggs by fresh epididymal sperm. Jap. J. Anim. Reprod. 16, 147-151.

Tsunoda, Y. \& Chang, M.C. (1977) In vitro fertilization of hamster eggs by ejaculated or epididymal spermatozoa in the presence of male accessory secretions. J. exp. Zool. 201, 445-450.

Yanagimachi, R. (1969a) In vitro capacitation of hamster spermatozoa by follicular fluid. $J$. Reprod. Fert. 18, 275-286.

Yanagimachi, R. (1969b) In vitro acrosome reaction and capacitation of golden hamster sperm by bovine follicular fluid and its fractions. $J$. exp. Zool. 170, 269280.

Yanagimachi, R. (1970) In vitro capacitation of golden hamster spermatozoa by homologous and heterologous blood sera. Biol. Reprod. 3, 147-153.

Yanagimachi, R. \& Chang, M.C. (1963) Fertilization of hamster eggs in vitro. Nature, Lond. 200, 281-282.

Yanagimachi, R. \& Chang, M.C. (1964) In vitro fertilization of hamster ova. J. exp. Zool. 156, 361376.

Received 29 March 1979 